\title{
ACROSS LEGAL LINES: JEWS AND MUSLIMS IN MODERN MOROCCO
}

Jessica M. Marglin, Across legal lines: Jews and Muslims in modern Morocco, New Haven, London: Yale University Press, 2016, 314 pp.

El libro de Jessica Marglin, Across legal lines: Jews and Muslims in modern Morocco, se basa fundamentalmente en el estudio del archivo de la familia Assarraf, una familia judeomarroquí de comerciantes acomodados de Fez, a caballo entre los siglos XIX y XX. El libro aborda las relaciones entre judíos y musulmanes en el ámbito judicial en el Marruecos pre-colonial y colonial. Marglin parte de las investigaciones existentes sobre el recurso de los judíos a la justicia de la sharia, la ley islámica, en el Imperio otomano, que han puesto en cuestión la idea de los judíos aislados dentro de su propio sistema legal en los países musulmanes. No obstante, en lugar de centrarse en los pleitos entre judíos sometidos a los tribunales islámicos, la autora se interesa sobre todo por los pleitos entre hebreos y mahometanos. A través de los Assarraf, Marglin observa las interacciones entre diferentes órdenes legales en Marruecos y como los judíos, fundamentalmente los más acomodados, navegaban con soltura entre varios sistemas judiciales. El pluralismo de sistemas legales en Marruecos aumentó a finales del siglo XIX con la irrupción de la justicia consular. La creación del Protectorado francés en 1912 puso fin a esta movilidad inter-jurisdiccional, lo que, en el caso de los judíos significó el fin de una de las vías de integración en la sociedad y el estado marroquí.

El libro está organizado en siete capítulos y un epílogo final. El capítulo primero ofrece una topografía de los tribunales y notarías existentes, incluyendo una descripción de su funcionamiento y de su encaje unos con otros. En primer lugar, la jurisdicción judía en el mellah, o barrio judío, de Fez, donde residía la familia Assarraf, con sus notarios, sofrim, y sus jueces, dayyanim, y los tribunales compuestos por más de un dayyan para resolver los casos más complicados, los batei din. En segundo lugar, la jurisdicción musulmana, a la que los Assarraf recurrían en sus pleitos con musulmanes durante el desarrollo de sus negocios. Las instituciones de la justicia islámica en Fez estaban concentradas en la ciudad vieja y consistía en los notarios, adules, los jueces, cadis, y un cuerpo de jurisconsultos o muftíes en las ciudades más importantes del país. Además, el Majzén ejercía un papel central como tribunal de apelación para los casos más graves, presidido por el 
propio sultán, además del papel que jugaban en el ámbito judicial local los gobernadores, pachas y caídes, nombrados por el sultán. Durante la segunda mitad del siglo XIX empezaron también a tener un papel significativo en los pleitos con ciudadanos o protegidos extranjeros los tribunales consulares.

El capítulo segundo está dedicado a las transacciones comerciales, a través de los pleitos en los que se vio envuelta la familia Assarraf. Marglin muestra como las interacciones cotidianas entre judíos y musulmanes no se limitaban al ámbito comercial, que ha sido más estudiado, sino que se extendía al ámbito judicial a través de procedimientos por reclamaciones comerciales. Estas reclamaciones, cuando involucraban a un musulmán, debían presentarse en los tribunales de la sharia. Al ser el ámbito comercial el espacio donde las interacciones entre musulmanes y judíos eran más frecuentes, por extensión este tipo de pleitos entre mahometanos e israelitas en los tribunales islámicos eran los más habituales también. Además, los comerciantes acomodados eran asimismo prestamistas de sus clientes, y tanto la documentación de los préstamos como los litigios por reclamaciones de préstamos entre judíos y musulmanes se sometían a la ley islámica.

En el capítulo tercero, Marglin aborda los procesos legales y litigios, de todo tipo, entre judíos, sometidos a la justicia islámica. Este capítulo pone de relieve que, a pesar del pluralismo legal en Marruecos, la jurisdicción islámica estaba por encima de la judía y, en caso de conflicto, tenía más peso un documento emitido por un adul musulmán que por un sofer judío, o por un juez musulmán que por uno hebreo. Así, no era infrecuente que los judíos acudiesen la notariado islámico para obtener un documento legal dado el mayor peso en los procesos judiciales de los escritos emitidos por los notarios y jueces islámicos. Pero, por otro lado, Marglin también muestra como la justicia musulmana en los pleitos entre judíos reconocía el valor de la ley judía, tanto mediante la aceptación de documentos emitidos por las instancias jurídicas judías como por el crédito otorgado a los aspectos legales existentes en la ley judía que diferían de la islámica. Más sorprendente es, sin embargo, el hecho de que, aunque en menor medida, algunos musulmanes recurrían también al sistema legal judío. Marglin presenta diferentes casuísticas en las que esto sucedía. Por ejemplo, cuando algunos musulmanes preferían protocolizar documentos legales con un sofer en vez de con un adul, si eso les favorecía en función de las diferencias legales entre la ley judía y la ley islámica.

El capítulo cuarto está dedicado a la justicia impartida por los órganos centrales del Majzén y por el mismo sultán, a la que recurrían judíos y musulmanes como si se tratase de una especie de tribunal de apelación cuando sus disputas no habían sido resueltas a su satisfacción a nivel de los órganos locales de justicia. Los judíos acomodados, como los Assarraf, acudían principalmente a la justicia del sultán sobre todo por deudas comerciales, pero también era frecuente apelar al Majzén en casos de robo o asesinato cuando la justicia local no podía o no quería resolver estos casos. Asimismo, los judíos recurrían al sultán cuando creían que los gobernadores locales nombrados por el Majzén estaban abusando de sus poderes judiciales. Así, el sultán mismo en persona se convertía en el garante último de la justicia en Marruecos. De esta forma, concluye Marglin, los judíos 
no solo obtenían justicia del sultán, sino que, al recurrir a él para resolver sus disputas reforzaban el vínculo entre éstos y el Majzén.

El capítulo quinto presta atención a la internacionalización de los procesos judiciales en los que se veían envueltos judíos a finales del siglo XIX. Gracias a la presencia de la Alliance Israélite en Marruecos, así como de la presión diplomática en el país, los judíos de Marruecos pudieron dar a sus pleitos una dimensión internacional, sin por ello dejar de utilizar los sistemas de justicia locales, la ley islámica, y la autoridad del Majzén, como lo habían hecho hasta entonces. Nuevamente vemos a través de la familia Assarraf el uso simultáneo o paralelo de distintos sistemas legales. Marglin demuestra, contra la creencia de que la irrupción del colonialismo supuso una ruptura de los judíos con el sultán, que, por el contrario, no solo represento una continuidad en la tradición de navegar entre diferentes órdenes legales, sino que, cuando se trataba de conflictos entre judíos y extranjeros, los judíos seguían confiando en la justicia del Majzén.

El capítulo sexto versa sobre la expansión de la extraterritorialidad en Marruecos desde mediados del siglo XIX. Marglin señala cómo la justicia consular no solo no sustituyó a las instituciones judiciales tradicionales en Marruecos, sino que expandió las posibilidades de opción tanto de judíos como de musulmanes si gozaban de una protección consular. De ese modo, los hebreos de Marruecos siguieron navegando entre sistemas judiciales distintos en función del que considerasen en cada momento que les podía ser más favorable. Los documentos notariales seguían circulando de una jurisdicción a otra como documentos probatorios, en particular los producidos por los adules, que se convirtieron en los documentos notariales por excelencia con independencia del ámbito judicial donde se fuesen a usar. De esa manera, incluso los representantes consulares utilizaron la autoridad de los documentos legales islámicos en favor de sus protegidos.

El capítulo séptimo se adentra en el Protectorado y muestra como las reformas introducidas por la administración francesa — no analiza la zona española de protectoradosignificaron el fin de la superposición de jurisdicciones y de la posibilidad de navegar entre diferentes sistemas legales del Marruecos pre-colonial, estableciendo rígidas fronteras entre el ámbito judicial de la sharia y de la halajá. Asimismo, la justicia que podían impartir los tribunales islámicos y rabínicos quedó reducida a cuestiones relativas al estatus personal y el derecho de familia, convirtiéndose en una mera sombra de las instituciones que habían sido antes de la imposición del Protectorado. Sin embargo, judíos y musulmanes se mostraron reticentes a estos cambios y siguieron requiriendo los servicios de sus tribunales religiosos como con anterioridad, para desesperación de las autoridades del Protectorado. Hasta principios de los años treinta estas reformas no se asentaron. Para entonces, dice Marglin, los judíos no solo no se encontraban en una situación de igualdad frente a los musulmanes, sino que perdieron la autonomía de sus tribunales religiosos de la que habían disfrutado bajo la autoridad del Majzén.

Finalmente, en el epílogo, Marglin rompe con el nivel de detalle y análisis de fuentes primarias, y, tras presentar de nuevo brevemente la tesis del libro, hace un breve resumen de la situación de los judíos durante el protectorado y la independencia de Marruecos hasta la actualidad, que no aporta nada nuevo. Hubiera sido más interesante, dado el ni- 
vel de detalle y maestría con el que Marglin se mueve, como sus protagonistas, entre varios sistemas legales, que el epílogo abordase, aunque brevemente, los principales cambios legislativos en el ámbito de notarías y tribunales tras la independencia de Marruecos y que impacto tuvieron en las opciones judiciales de judíos y musulmanes.

No obstante, este algo desafortunado final, y la falta de análisis del caso español, que, aunque imitó en muchos casos las políticas del protectorado francés, pasó sin embargo durante el siglo Xx por procesos políticos bien distintos (España no participó directamente en la Segunda Guerra Mundial y no aplicó una legislación antijudía en su zona de protectorado, pero sí las políticas de una dictadura de veinte años sobre esa región), no quita méritos a una investigación excelente y necesaria, con un redactado claro y directo en la forma de abordar un tema tan complejo y dinámico, además de la maestría y soltura con la que Marglin se mueve entre los hasta cuatro sistemas legales distintos. Un libro imprescindible y necesario para conocer un poco más el día a día de las relaciones entre judíos y musulmanes en Marruecos entre finales del siglo XIX y principios del siglo XX. Es quizás, después de la investigación de Mohammed Kenbib, sobre judíos y musulmanes en Marruecos entre mediados del siglo XIX y mediados del siglo XX, la investigación más detallada y novedosa en este sentido.

Maite Ojeda-Mata

The Parkes Institute University of Southampton 